\title{
Maternal and Alloparental Discipline in Atlantic Spotted Dolphins (Stenalla frontalis) in the Bahamas
}

\author{
Meghan R. Weinpress ${ }^{1,2 *}$ and Denise L. Herzing ${ }^{1,2}$ \\ ${ }^{1}$ Florida Atlantic University \\ ${ }^{2}$ Wild Dolphin Project \\ *Corresponding author (Email: MGalipeau@scaquarium.org)
}

Citation - Weinpress, M. R., \& Herzing, D. L. (2015). Maternal and alloparental discipline in Atlantic spotted dolphins (Stenella frontalis). Animal Behavior and Cognition, 2(4), 348-364. doi: 10.12966/abc.11.04.2015

\begin{abstract}
Maternal and alloparental disciplinary behavior were examined in a community of Atlantic spotted dolphins (Stenella frontalis) on Little Bahama Bank, Bahamas. An operational definition of discipline was created and analyses were performed of underwater behavior by spotted dolphins. Results indicated that both mothers and alloparents performed discipline towards juveniles and calves in their community. Both males and females were observed performing and receiving discipline. Disciplinarians were significantly more likely to be adults than juveniles, and receivers of discipline were significantly more likely to be calves than juveniles. Pursuit, contact, and display behaviors were used in discipline, however pursuit behaviors were most often observed. Variables such as age class, sex, and parity were not found to influence how discipline was implemented, nor outcome. The durations of all disciplinary pursuits analyzed were under thirty seconds.
\end{abstract}

Keywords - Spotted dolphins, Discipline, Allomaternal care, Maternal care

Discipline is a broad category of behavior that involves punishment and the threat of punishment, and encompasses parental and alloparental behavior. Discipline is traditionally defined as punishment or penalty imposed for an unwelcome behavior with intent to extinguish that behavior (Clutton-Brock \& Parker, 1995; Hill, 2009; Webster's Merriam Dictionary, 2011). Discipline has been thoroughly studied in human behavior, however little discipline research has focused on other organisms (Hoffman \& Saltzstein, 1967; Kircaali-Iftar, 2005; McLoyd \& Smith, 2002; Regalado, Sareen, Inkeles, Wissow, \& Halfon, 2004). In animals, behaviors that decrease the survivorship of the individual or group often elicit punishment or discipline, and the receiver is often a subordinate to the punisher (Clutton-Brock \& Parker, 1995). Factors such as sex, age, and kinship have been observed to influence how punishment/discipline is executed (Clutton-Brock \& Parker, 1995). Discipline has been examined in animal behavior studies as a facet of maternal behavior (Herzing, 1996; Hill, Greer, Solangi, \& Kuczaj, 2007; Hill, 2009; McCowan \& Reiss, 1995). This suggests disciplinary behavior may function to increase the fitness of an individual or group by reducing the frequency of behaviors that decrease survival or reproduction (Clutton-Brock, 1991; Clutton-Brock \& Parker, 1995; Hill, 2009). Few studies have defined discipline; however existing definitions are similar in meaning. Herzing (1996) defined discipline for Atlantic spotted dolphins (Stenella frontalis) as an individual reprimanding another individual for punishment or to re-establish order. Hill (2009) also defined maternal discipline for cetaceans, describing it as a type of behavior in which the mother aims to reduce the frequency of a specific behavior occurring in their calf.

A variety of discipline behaviors have been described for several delphinid species (Herzing, 1996; Hill et al., 2007; Hill, 2009; McCowan \& Reiss, 1995). Captive beluga whale and bottlenose dolphin mothers pinned their calves to the bottom of the pool and held calves either above or below the water's surface (Hill, 2009; Hill et al., 2007; McCowan \& Reiss, 1995). A specialized vocalization was 
reported by McCowan and Reiss (1995) in captive bottlenose dolphins (Tursiops truncatus) as a precursor to disciplinary behavior. Researchers reported mothers and "aunting females" used this vocalization in concert with disciplinary behavior to retrieve calves after separations from adults (McCowan and Reiss, 1995). Mann and Smuts (1998) found that wild bottlenose dolphin mothers chased their calves when calves swam away from their mother during the first week of life. Wild Atlantic spotted dolphin mothers chased their calves as well, often inverting their bodies during the chase (Herzing, 1996). Within the chase, mothers were observed to use echolocation on the genital area of the calf, and sometimes hit the calf with their rostrum. In the present study, videos were analyzed to examine discipline in a community of Atlantic spotted dolphins. Disciplines were examined for 1) Category in which behavior of dolphin falls, 2) Behaviors used by different individuals, and 3) How type of discipline and individual performing discipline were related to the outcome of discipline. Since the study considers discipline within the framework of parental care, analyses focused on older individuals disciplining calves or juveniles.

\section{Study Site}

\section{Method}

The study area was located on Little Bahama Bank, north of Grand Bahama Island (Figure 1). The white sand bank encompasses an area of $480 \mathrm{~km}^{2}$ and ranges from 6 to $16 \mathrm{~ms}$ in depth. It is surrounded by deeper water greater than $500 \mathrm{~m}$ in depth. This location is unique with shallow, clear water that allowed researchers to identify and record dolphins using video and still photography (Herzing, 1996; 1997).

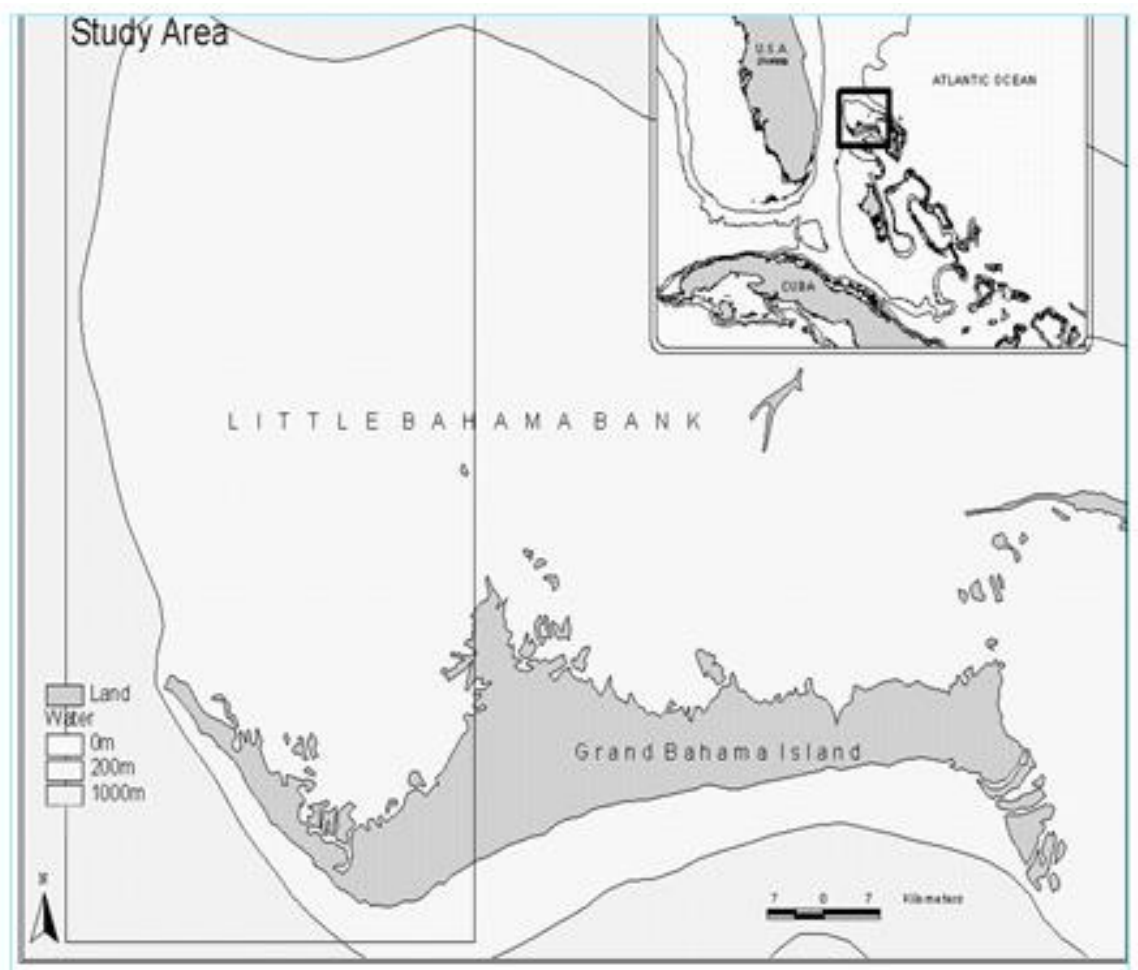

Figure 1. Study site. Little Bahama Bank and Grand Bahama Island in the Bahamas.

A resident community of Atlantic spotted dolphins (Stenella frontalis) has been studied since 1985 by the Wild Dolphin Project (WDP) and has identified over 200 individuals based on spot patterns and other body markings. Sex was determined when possible based on observation of the genital slit. Herzing (1997) classified Atlantic spotted dolphins into four age classes based on spot development with maturity. Age of each individual is estimated based on spot development, or known from tracking the 
animal since birth. Neonates and calves ages $1-3$ were termed two-tone, characterized by a lack of spots and a gray and white overall coloration. Juvenile dolphins, age $4-8$, were considered speckled, young adults aged $9-15$ years were mottled, and adults aged 16 and above were classified as fused. Most females reach sexual maturity during the mottled years (Herzing, 1997). It is unknown when male Atlantic spotted dolphins reach sexual maturity (Green et al., 2011). This study focused on spotted dolphins ranging in age from neonates to adults. On several occasions, age classes were combined to include juveniles (calves and juveniles) and adults (young and older adults).

\section{Data Collection}

Dolphin behavior was recorded with various underwater video cameras (including Sony XR 550, Sony CCDV9 8mm, or Yashica KXV1u 8mm) with an attached hydrophone. Dolphin behavioral data was collected using ad lib, behavioral event, and focal sampling methods (Altman, 1974). Underwater photographs were used to identify the dolphins present during the encounter, and video recordings were used to confirm those identities.

Data for this study were selected from the WDP long term database, which includes a photo identification catalog of individuals, written encounter details, video footage, and supplemental video logs.

\section{Behavioral Definitions}

Discipline was defined as an instance in which an older dolphin directed an actual or threatened stimulus to a younger dolphin in an attempt to immediately change the younger individual's behavior. Successful discipline resulted in the immediate and sustained change of the receiver's behavior. Discipline did not include instances where aggression was elevated or prolonged, nor did it culminate in copulation or related mating behaviors. The individual dolphin that performed the disciplinary act was identified as the "disciplinarian. The "receiver" was defined as the dolphin towards which the disciplinary act was directed.

"Precursor behavior" was defined as the receiver's activity within ten seconds before discipline occurred. All behaviors in this category were scored as behavioral events. "Outcome behavior" was defined as the activity of the receiver within ten seconds after the disciplinary event. All behaviors in this category were also scored as behavioral events. Finally, the overall "discipline sequence" was a composed of the precursor behaviors of the receiver, the disciplinary event itself, and the outcome, or subsequent behaviors of the receiver. The operational definitions of all independent variables and behavioral categories are listed in Tables 1 and 2.

The disciplinarian was either a mother or alloparent. The mother was defined as the biological parent of an offspring, and was determined by visible pregnancies in females followed by resightings of female with a nursing calf (Herzing, 1997). All mothers were mottled (young adults) or fused (adult), as reproductive maturity occurred during the mottled age class. An alloparent was defined as a speckled (juvenile), mottled, or fused male or female dolphin that directed disciplinary behavior toward another dolphin that was not its known biological offspring. The receiver was defined as an immature dolphin, either a calf (two-tone age class) or juvenile (speckled age class). Discipline between adults was not measured in the current study. Only discipline directed from an older dolphin to younger dolphin was analyzed, which included discipline between a juvenile and a calf because females may practice parenting skills such as discipline in their juvenile years.

A discipline ethogram was developed by modifying of the existing WDP ethogram (Herzing, 1995), and consisted of behavioral events performed by both the disciplinarian and the receiver (Table 2). Discipline behavior was defined using three behavioral categories: 1) Pursuit, 2) Contact, and 3) Display. Behavioral events performed by the receiver before and after discipline were included in the ethogram under each behavioral category, as were modifiers used to further describe the behavioral events observed (Table 2). The outcome of each discipline sequence was defined as how or if the behavior of the receiver 
changed after the discipline behavior ended. Outcome was scored as one of the following: 1) Behavior of the receiver stayed the same, 2) Behavior of the receiver stayed the same but energy level increased or decreased 3) Behavior of the receiver changed with an increased energy state, 4) Behavior of the receiver changed with a decreased energy state, 5) Disciplinarian performed more discipline, or 6) Other. An outcome qualified as "other" if the behavior of the receiver did not fall into one of the previous categories. Energy level was considered because behaviors such as swimming were often involved in analysis (i.e. chase, inverted chase). Dolphins swim almost continuously; thus it was necessary to include a quantifiable measure, such as energy level, to examine the response of the receiver to a disciplinary act. Energy level was measured based on number of fluke beats in five seconds, and number of directional changes in five seconds. Discipline was considered successful if the behavior of the receiver changed (outcomes $3 \& 4$ ) or if energy level of the receiver changed (outcome 2). During analysis, more emphasis was placed on receivers' behavioral changes rather than energy changes. Changes in behavior were measured with the specific direction in energy level (i.e., increase or decrease), whereas the type of energy level change was not specified when no behavioral change occurred in the receiver following discipline.

Table 1

Independent Variables: All Subjects Involved in Discipline Sequences Including Disciplinarians and Receivers

\begin{tabular}{|c|c|}
\hline Independent Variable & Description \\
\hline A. Disciplinarian ID & Identification of dolphin performing disciplinary behavior \\
\hline \multicolumn{2}{|l|}{ Mother } \\
\hline \multicolumn{2}{|l|}{ Non-mother } \\
\hline B. Disciplinarian Sex & Sex of disciplinarian \\
\hline \multicolumn{2}{|l|}{ Female } \\
\hline \multicolumn{2}{|l|}{ Male } \\
\hline C. Disciplinarian Age Class & Age classes based on Herzing (1997) \\
\hline \multicolumn{2}{|l|}{ Speckled } \\
\hline \multicolumn{2}{|l|}{ Mottled } \\
\hline \multicolumn{2}{|l|}{ Fused } \\
\hline D. Parity of Disciplinarian & Number of times female has given birth \\
\hline Nulliparous & Female has never given birth \\
\hline Primiparous & Female has given birth one time \\
\hline Mulitparous & Female has given birth more than once \\
\hline K. Receiver Sex & Sex of receiver \\
\hline \multicolumn{2}{|l|}{ Female } \\
\hline \multicolumn{2}{|l|}{ Male } \\
\hline L. Receiver age class & Age classes based on Herzing (1997) \\
\hline \multicolumn{2}{|l|}{ Two-tone } \\
\hline \multicolumn{2}{|l|}{ Speckled } \\
\hline M. Kinship of Receiver & Genetic relationship between disciplinarian and receiver \\
\hline \multicolumn{2}{|l|}{ Yes } \\
\hline \multicolumn{2}{|l|}{ No } \\
\hline Unknown & \\
\hline
\end{tabular}


Table 2

Behavioral Events: Operational Definitions and Behavioral Ethogram

\begin{tabular}{|c|c|}
\hline Category & Description \\
\hline Pursuit & Behaviors in which one dolphin or a group of dolphins follow another \\
\hline Chase & $\begin{array}{l}\text { One dolphins, or a group of dolphins chasing each other in fast, medium, or slow } \\
\text { chases }\end{array}$ \\
\hline Inverted Chase & Following dolphin is inverted while chasing another \\
\hline Contact & Behavior in which physical contact is made between dolphins involved \\
\hline Hold Down & Dolphin or group of dolphins hold down another on the bottom \\
\hline Charge & Two or more dolphins charge, head to head, sometimes making contact \\
\hline Tail Slap & A tail slap that makes contact with another dolphin's body \\
\hline Tail Swipe & One dolphin swipes the face/body if another dolphin \\
\hline Rostrum Bop & One dolphin hits another with its rostrum \\
\hline Rostrum Joust & Dolphins dueling with rostrums \\
\hline Pec to & One dolphin is rubbing pectoral fin to corresponding body part of second dolphin \\
\hline \multicolumn{2}{|l|}{ Pec/Head/Genitals/Flank/Belly/Fluke } \\
\hline Pec body swim & $\begin{array}{l}\text { One dolphin sustains contact with another pec fin touching mid body of other while } \\
\text { swimming }\end{array}$ \\
\hline Nursing & Infant receives milk from mother; mother or calf initiates \\
\hline Tail bite & One dolphin bites another's tail, usually in chase \\
\hline Bite & One dolphin bites or rakes another \\
\hline Passive Float & Dolphin floats passively while others nudge it or roll it \\
\hline Contact Swim & One dolphin swims with pec fin to body with another \\
\hline Group Cluster & $\begin{array}{l}\text { Two or more dolphins form a tight, within body contact unit and synchronize swim, } \\
\text { breathing, and vocalizing }\end{array}$ \\
\hline Rostrum Push & One dolphin contacts or pushes another with rostrum \\
\hline Display & $\begin{array}{l}\text { Behaviors in which one dolphin directs a body orientation to another dolphin without } \\
\text { physical contact }\end{array}$ \\
\hline Jaw snap & Dolphin opens and shuts jaw rapidly, directed toward another dolphins \\
\hline S-posture & Dolphin is arched so that rostrum is up, body is down and flukes are up \\
\hline Head to Head & Dolphins take head to head position; motion or stationary position \\
\hline Inverted Head to Head & One or more dolphin orient in a head to head position, body posture inverted \\
\hline Open Mouth & One or more dolphin open their mouth toward another \\
\hline Reunite & One dolphin rejoins another after a departure away \\
\hline Pout & Dolphin hangs in relaxed arch at surface, facing away from others \\
\hline Group Dash & Two or more dolphins accelerate rapidly underwater \\
\hline Erratic Swim & $\begin{array}{l}\text { Dolphin is swimming through water erratically, usually in circles and contained in } \\
\text { small area }\end{array}$ \\
\hline \multicolumn{2}{|r|}{ STl } \\
\hline Group Tussle & Dolphins in general body tumble \\
\hline \multicolumn{2}{|l|}{ Aerial Behavior } \\
\hline Breach Side/Belly & Dolphin leaps out of the water and lands on side/belly \\
\hline Tail Slap & Dolphin hits surface of water with ventral fluke \\
\hline Inverted Tail Slap & $\begin{array}{l}\text { Dolphin hits surface of water with dorsal fluke while inverted on surface or under } \\
\text { surface }\end{array}$ \\
\hline Exit/Re-enter & Dolphin exits and reenters same spot while being chased out of the water \\
\hline \multicolumn{2}{|l|}{ Vocalizations } \\
\hline Excitement Vocalizations & Burst pulse vocalization with overlapping signature whistle \\
\hline Signature Whistle & Frequency modulated whistle \\
\hline Genital Buzz & High repetition-rate clicks \\
\hline Squawk & Broad band burst pulse vocalization \\
\hline Proximity during pursuit & Proximity of disciplinarian during chase or inverted chase \\
\hline Near & Less than two adult body lengths \\
\hline Far & More than two adult body lengths \\
\hline Other dolphins present during discipline & $\begin{array}{l}\text { Other dolphins present during discipline and may or may not participate in discipline } \\
\text { behavior }\end{array}$ \\
\hline
\end{tabular}




\section{Analyzing Discipline Behavior}

Videos were selected from the WDP's long term database between 1991 through 2009. Video clips were analyzed using the discipline ethogram. The ethogram was uploaded into Observer XT 7.0 to observe and analyze the video clips of discipline. All behavioral activity observed in a discipline sequence was recorded as a mutually exclusive behavioral event which allowed the frequency of occurrence of that specific behavior to be measured (Martin \& Bateson, 2007). The behavioral activity of the receiver before and after the disciplinary act were scored as behavioral events (discrete occurrences), and allowed the recorder to view any changes in the receiver's behavior that occurred relative to the disciplinary act. The beginning of the specific disciplinary behavioral activity performed by the disciplinarian was scored as a behavioral event, as was the cessation of the disciplinary act. Although behavior was not scored as a state, the durations of behavioral activities such as chases and hold-downs were manually derived by measuring the time between the behavioral event scored at the start of the disciplinary behavior, and the behavioral event scored at the end of the disciplinary event. Figure 2 is a visual representation of the discipline sequence including precursor, disciplinary, and outcome behavior.

All videos were scored by the first author, and $25 \%$ of the videos $(n=6)$ were scored by the second, trained observer to test for inter-observer reliability. There was a significant correlation between the all observations by the first and second observers (all $r^{2} \geq 0.92$ ).

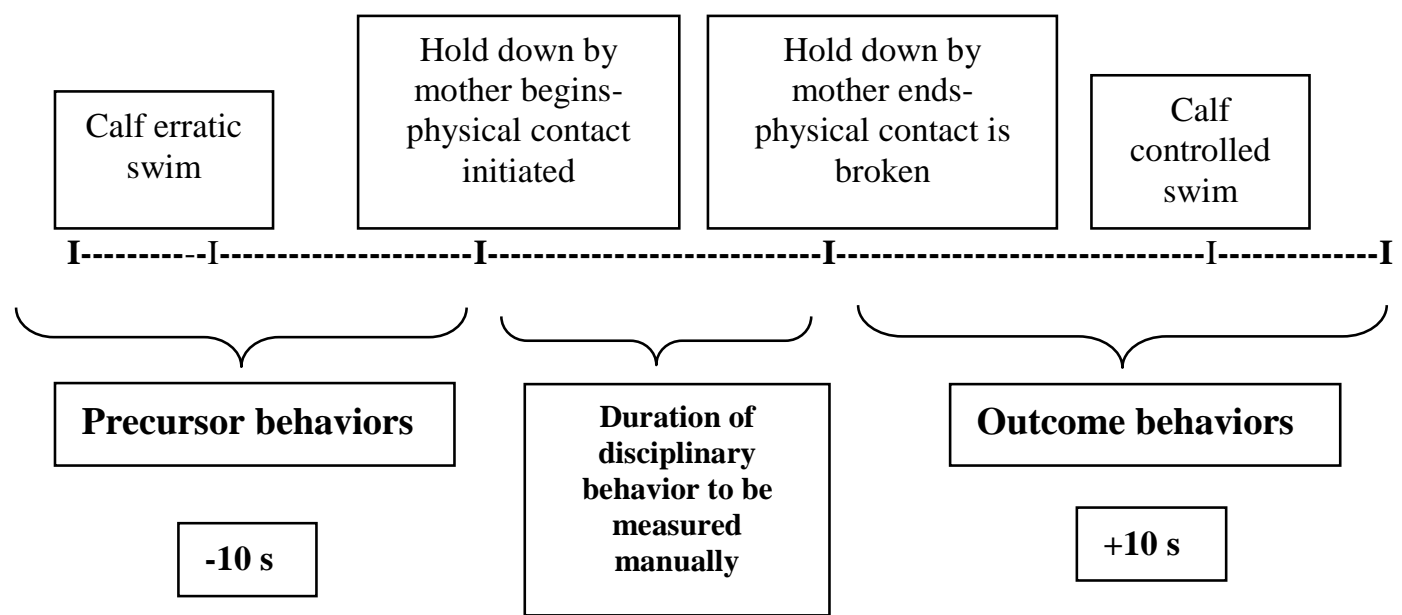

Figure 2. Disciplinary sequence. Analysis of disciplinary behavior with precursor and outcome behavior using behavioral events. 


\section{Description of Disciplinarians}

All disciplinarians. Of the 31 videos scored for discipline, 24 met the criteria set for this project and were used in analysis. In the 24 complete discipline sequences analyzed, $48 \%$ of disciplinary sequences were performed by mothers, and $48 \%$ by alloparents (male and female) (Table 3 ). When age class was merged to compare adults (mottled and fused) vs. juveniles (speckled) for mother and alloparent disciplinarians, there were significantly more adult disciplinarians than juvenile disciplinarians $(p<0.05)$ (Table 4).

Table 3

Subjects Involved in Discipline

\begin{tabular}{ccccc}
\hline Disciplinarians & Two-Tone & Speckled & Mottled & Fused \\
\hline Mothers & & & & \\
Female & N/A & 0 & 7 & 4 \\
Males & N/A & N/A & N/A & N/A \\
& & & & \\
Alloparents & & & 1 & 4 \\
Female & N/A & 0 & 0 & 3 \\
Male & N/A & 4 & 0 & 0 \\
Unknown & N/A & 1 & & \\
Receivers & & & & N/A \\
Female & 8 & 2 & N/A & N/A \\
Male & 12 & 1 & N/A \\
Unknown & 0 & 0 & & N/A \\
\hline
\end{tabular}

Note. Includes mother and alloparent disciplinarians, and receivers of discipline.

Table 4

Comparison of Mother and Alloparent Disciplinarians

\begin{tabular}{lll} 
Group & $\boldsymbol{N}$ & $\boldsymbol{p}$ \\
\hline Age Class & & 0.04 \\
Juvenile*Adult & 24 & 0.01 \\
Speckled*Mottled*Fused & 24 & 0.004 \\
Mottled*Speckled & 16 & 0.06 \\
Mottled*Fused & 19 & 0.24 \\
Fused*Speckled & 16 & 1 \\
Parity & & 16 \\
Primiparous*Multiparous & 16 & \\
\hline $\begin{array}{l}\text { Note. Results from Fisher exact test in which age class and parity were compared for significance. Bold indicates a significant } \\
\text { difference }(p<0.05)\end{array}$ &
\end{tabular}


Description of receivers of discipline. In 23 discipline sequences analyzed in which sex of receiver was known, mothers and alloparents disciplined two-tones significantly more than speckled individuals $\left(\chi^{2}=12.61\right.$, df $\left.=1, p<0.05\right)$. In regards to sex of the receiver, there was no significant difference found in how mothers and alloparents disciplined males versus females $(p>0.05)$

Behaviors used in discipline

A behavioral event from the pursuit behavioral category (including chase or inverted chase) was observed in 17 of the 24 complete discipline sequences analyzed (Table 5). Inverted chases were observed frequently as well as regular chases discipline. Behavioral events from the display and contact categories were observed in equal proportions (Table 5).

Table 5

Behaviors Used in Discipline

\begin{tabular}{ll}
\hline Behavior & Frequency of Occurrence \\
\hline Pursuit & 17 \\
Chase & 6 \\
Inverted Case & 11 \\
Display & 4 \\
Open Mouth & 3 \\
Tail Slap & 1 \\
Contact & 3 \\
Tail Swipe & 2 \\
Hold Down & 1 \\
\hline
\end{tabular}

\section{Analysis of Pursuit Behavior}

Behavioral events in the pursuit behavioral category (chase or inverted chase) were observed in 17 discipline sequences. The mean duration of pursuit was $10.01(S D=6.19)$ seconds. There was no significant difference between the pursuit durations means of mother and alloparent disciplinarians $(t(15)$ $=1.85, p>0.05)$, (Table 6$)$.

Twelve of the seventeen pursuit behavioral events were classified as an inverted chase. The mean inverted chase duration for all disciplinarians was 8.31 seconds $(S D=4.20)$. Figure 3 depicts the average duration of inverted chase for alloparents and mothers. There was no significant difference between the mean durations of mother and alloparent inverted chases used in discipline $(t(10)=1.05, p>0.05)$ (Table $6)$. 
Table 6

Pursuit Means Statistical Analysis

\begin{tabular}{|c|c|c|c|c|}
\hline Group & $N$ & $\mathbf{t}$ & df & $p$ \\
\hline \multicolumn{5}{|l|}{ All Pursuit } \\
\hline Mothers*Alloparents & 17 & -1.84 & 15 & 0.08 \\
\hline \multicolumn{5}{|l|}{ Mothers Only } \\
\hline Mottled*Fused & 8 & 0.237 & 6 & 0.82 \\
\hline Multiparous*Primiparous & 8 & NA & NA & NA \\
\hline \multicolumn{5}{|l|}{ Alloparents Only } \\
\hline Male*Female & 8 & 0.622 & 6 & 0.56 \\
\hline Juvenile*Adult & 9 & 1.961 & 7 & 0.09 \\
\hline \multicolumn{5}{|l|}{ Inverted Chase All } \\
\hline Mothers*Alloparents & 11 & -1.05 & 10 & 0.32 \\
\hline \multicolumn{5}{|l|}{ Inverted Chase Mothers Only } \\
\hline Mottled*Fused & 8 & -0.57 & 6 & 0.59 \\
\hline Multiparous*Primiparous & 8 & NA & NA & NA \\
\hline Successful*Unsuccessful & 14 & -1.76 & 12 & 0.1 \\
\hline
\end{tabular}

Note. Results from independent measures t test in which pursuit means were compared.

* groups being compared

\section{Duration of Inverted Chase}

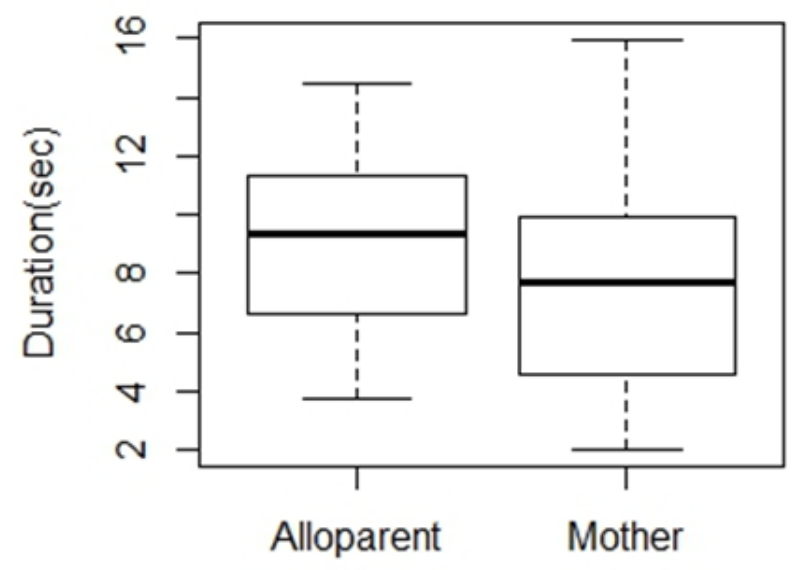

Disciplinarian

Figure 3. Mean duration of inverted chase. Includes mean duration of inverted chase for mother and alloparent disciplinarians $(N$ =12). 


\section{Success in Discipline}

For analysis, success was subcategorized into the following subcategories: 1) Success of all disciplinarians, 2) Success of behaviors used in discipline, 3) Success of mothers versus alloparents, and 4) The success of mothers as a group and success alloparents as a group. Success in discipline was determined in 24 discipline sequences. Fifty-four percent of disciplinary attempts were successful. There was no significant difference in the success between each behavioral category ( $p>0.05)$ (Table 7). Mothers were successful in sixty-two percent of discipline and alloparents were successful in forty-five percent of discipline. However, there was no significant difference in the success of mothers versus alloparents in discipline $(p>0.05)$ (Table 7). Age class, sex, and parity were not found to be significant predictors of success in discipline $((p>0.05)$ (Table 7)).

Table 7

Disciplinarians Success Statistical Analysis

\begin{tabular}{lll}
\hline Group & $\boldsymbol{N}$ & $\boldsymbol{p}$ value \\
\hline All disciplinarians & & \\
Mothers*Alloparents & 24 & 0.682 \\
Age Class (Speckled*Mottled*Fused) & 24 & 0.73 \\
Age Class (Juvenile*Adult) & 25 & 1 \\
Parity (Primiparous*Multiparous) & 18 & 1 \\
Sex (Male*Female) & 24 & 0.65 \\
Behaviors (Contact*Pursuit*Display) & 24 & 0.45 \\
\hline${ }^{*}$ groups being compared & &
\end{tabular}

Discussion

\section{Description of Participants}

Disciplinarians. In the spotted dolphin community on Little Bahama Bank, adults were significantly more likely to perform discipline than juveniles. Disciplinarians were equally likely to be mothers and alloparents, and both female and male dolphins were observed to perform discipline. Despite a dearth of animal behavior research that describes who performs discipline in dolphin communities, there are similarities between the spotted dolphins on Little Bahama Bank and other marine mammals in terms of what members of a community participate in parental and alloparental behavior (Herzing 1996; Hill 2003, 2009; McCowan \& Reiss, 1995).

One of the main findings of this study was that adults are more likely to perform discipline than juveniles. However, the majority of dolphins sampled in this study were adults, as about half of the dolphins studied were mothers. Atlantic spotted dolphins do not reach sexual maturity until their young adult years (mottled age class), and would obviously not be able to give birth before becoming adults (Herzing, 1997). Juvenile disciplinarians were also included in the sample, but were not observed performing discipline as often as adults. Although juvenile females have been observed providing discipline to calves in the field (D. Herzing, personal communication), they were not represented in this research due to lack of video examples that met criteria for analysis. Only male juveniles were observed disciplining calves in this study, and may account for the low proportion of juveniles that performed discipline relative to adults. The possibility that juveniles, specifically females, were underrepresented in this study is high considering juvenile females have been reported to be more attracted to young and more likely to perform parental care towards young than males in human and non-human primate species, as well as in cetacean species (Cords, Sheehan, \& Ekernas, 2010; Herman, Measday, \& Wallen, 2003; 
Maestripieri \& Pelka, 2002; Mann \& Smuts, 1998; Waitt, Maestripieri, \& Gerald, 2007). Nonetheless, discipline is often considered a component of parental care, suggesting reproductively active adults are more likely to be reported performing discipline. In social species such as dolphins, with age often comes acquisition of survival skills and knowledge of social roles, which may be related to imparting parenting/disciplinary behavior towards younger animals in their social group.

Examining the sex of disciplinarians revealed that both males and females performed discipline in the spotted dolphin community. This suggests that although male spotted dolphins have not been reported to show paternal behavior, they may still gain fitness benefits by investing in the young of their community. The high energetic cost of reproduction may elicit parental behavior in females (CluttonBrock, 1991). Males however, may have a different motivation for disciplining a young dolphin. Their motivation may be more related to the fitness costs and benefits balanced in social living. Males, and alloparents in general, may increase their fitness by influencing the behavior of conspecifics in their social group, as they would when disciplining another dolphin. Studies on punishment in humans and primates have suggested that punishment evolved as a way to encourage cooperation and reduce selfish behavior in social groups (Boyd, Gintis, \& Bowles, 2010; Gardner \& West, 2004; Jensen, 2010; Riedl, Jensen, Call, \& Tomasello, 2012; Seymour, Singer, \& Dolan, 2007). A review of punishment in animal groups (Clutton-Brock \& Parker, 1995) suggested that punishment from a dominant animal to a subordinate can increase the dominant animal's fitness. A dominant animal can use punishment to reduce unwanted behaviors by subordinate group members that would otherwise decrease the fitness of the dominant individual (Clutton-Brock \& Parker, 1995). Researchers have suggested that the cost of punishment to the dominant individual is low considering the benefit that it would gain in terms of its own fitness (Boyd et al., 2010; Clutton-Brock \& Parker, 1995; Gardner \& West, 2004). The punisher is generally able to punish at little cost, since the receiver is already a subdominant individual. These concepts of punishment are very similar to the definition of discipline that was developed for this study. In this study, the dominant animal is the older, more experienced mother, male or alloparent, and the subordinate animal is the young calf or juvenile disciplined. A spotted dolphin calf is smaller in size than juveniles and adults, and the risk of retaliation is low from an inexperienced calf or juvenile. The dominant punisher could then benefit from the disciplinary energy expenditure by reducing the frequency of occurrence of the unwanted behavior, and increase its own fitness. A variety of individuals providing discipline in the spotted dolphin community, as well as the correlation between punishment and cooperative behavior in a social group, suggest that disciplining another group member may not just be a benefit a mother, but also to the social groups as a whole.

\section{Receivers}

In the spotted dolphin community of Little Bahama Bank, calves received significantly more discipline than juveniles. There are several reasons why this likely occurred. Spotted dolphin calves are age three and under (Herzing, 1997), and are dependent on their mothers for survival and integration into their social group. This is the case for many social mammals including other dolphin species and primates (Maestripieri, 2011; Mann, Stanton, Patterson, Bienenstock, \& Singh, 2012; Rendell \& Whitehead, 2001). Calves are also reported to spend the majority of their time with their mothers for the first three years of life (Herzing \& Brunnick, 1997), until subsequent offspring are born. Many dolphin studies, including those on this spotted dolphin community, have indicated that mother/calf interaction and maternal care are highest in the first few months to year of an offspring's life (Hill et al., 2007; Mann \& Smuts, 1998, 1999; Miles \& Herzing, 2003). Thus parental care behaviors, including discipline, may be performed with higher frequency in the early years of a spotted dolphin calf's life, as opposed to their juvenile years. Furthermore, dolphin calves have the least life experience of any age class and are thus more likely to 
engage in behaviors maladaptive to their survival. By the time they become juveniles, previous years of discipline may result in a lower occurrence of behaviors that reduce their chances for survival.

Alloparents may have disciplined calves more than juveniles because they were associating with other mothers. Herzing and Brunnick (1997) reported that females are most likely to associate with other females of similar reproductive status; for example, females with young calves are likely to be in the company of other females with young calves. These groups of mothers may discipline their own calves, and those of their close associates. In social living animals such as dolphins, the behavior of each individual may affect the fitness of others in the group (Clutton-Brock \& Parker, 1995; Lusseau, 2007). Misbehaving calves would not only affect their own survival, but that of their mother and the social unit as a whole. Groups of mothers and calves would benefit from ensuring each calf in a social group behaved in an appropriate manner.

\section{Behavioral Descriptions and Analyses}

Behaviors used in discipline-all disciplinarians. The behaviors used in discipline included pursuit behaviors, contact behaviors, and display behaviors. Though not statistically significant, a notable trend was observed; the majority of disciplinary behaviors were pursuit behaviors, while display and contact behavior were used less often.

Pursuit behaviors were frequently observed during disciplinary behavior, and were successful more than half the time (59\% success). All chases by mothers and alloparents were relatively short; every pursuit measured lasted less than thirty seconds. Considering the mechanics of a disciplinary chase, the fleeing receiver would have to change their behavior immediately in order to avoid another dolphin "catching" them. If the unwanted behavior was altered at the onset of pursuit, there would be no further need by the disciplinarian to continue to expend energy in the chase. Pursuit is an energetically expensive behavior, and a longer chase would require the use of more energy than a short chase. If a disciplinarian implemented a short, efficient chase, they may be able to change the behavior of the receiver without expending excess energy that they would otherwise allocate to other behaviors.

Many of pursuit behaviors observed in this study were inverted chases, in which the disciplinarian inverted their body throughout the entirety of the pursuit. It is unclear as to why disciplinarians inverted their bodies during many chases, or what additional benefit inverted chasing had compared to chasing in the upright position. The spotted dolphins in the Bahamas are the only cetacean community in which inverted chasing has been reported during discipline (Herzing, 1996). Inverted swimming has been identified in several dolphin species in a variety of behavioral contexts including foraging, play, and aggression (Ballance, 1992; Bearzi \& Politi, 1999; Geise, Gomes, \& Cerqueira, 1999; Kuczaj, Makecha, Trone, Paulos, \& Ramos, 2006; Herzing, 1996), as well as in the spotted dolphin community in the Bahamas during courtship and aggression (Herzing, 1996). It is possible that being inverted is advantageous regardless of behavioral context in terms of sensory perception through vision and/or echolocation. Dolphins have ventral and rostral binocular vision ("Functional Systems," 2008) and may gain a better view of their fleeing target if they invert their bodies and look upwards utilizing their stereoscopic vision. Odontocete echolocation has also been described in detail, and it has been shown that dolphins emit their most focused beam of echolocation at a five degree upward angle from their head ( $\mathrm{Au}$, 1997; Herzing \& dos Santos, 2004). Inverting their bodies may allow them to angle this focused beam of echolocation more directly toward their fleeing target. Herzing (1996) also reported that spotted dolphin mothers "buzzed" their calf"s genitals with echolocation during inverted discipline chases; inversion of the body may again allow them to direct their strongest beam of echolocation towards the genitals of the receiving calf. This genital buzzing has also been suggested to produce a painful physical sensation to the 
receiver in this highly sensitive area, which could add to the potency of the discipline being inflicted on the receiver (Herzing, 1996; Herzing \& dos Santos, 2004).

Display behaviors were observed in a smaller proportion relative to pursuit behaviors. There are several reasons why this may have occurred. Compared to both contact and pursuit behaviors, display behaviors (such as an open mouth) did not require proximity to the receiver nor physical contact from the disciplinarian. The lack of proximity necessary during display behaviors may make it more challenging to change the unwanted behavior of the receiver. In addition, the success rate of behaviors from the display category was less than half (25\%), which could discourage the use of display in future discipline.

Contact behaviors such as tail swipes and hold downs were observed relatively less often than both pursuit and display in discipline. This result is unexpected considering contact behaviors had the highest relative success rate of all disciplinary behavioral categories $(67 \%)$. Contact behaviors could be an effective yet dangerous disciplinary tactic, resulting in infrequent use by disciplinarians. Contact behaviors are often observed in aggression in dolphins (Connor, Smolker, \& Richards, 1992; Cusick, 2012; Herzing \& Johnson, 1997; Scott, Mann, Watson-Capps, Sargeant, \& Connor, 2004), and behaviors such as body slamming and biting have been known to cause bodily harm or even death to receivers (Dunn, Barco, Pabst, \& McLellan, 2002; Scott et al., 2004). However, these behaviors are most often reported between adults (Connor et al., 1992; Scott et al., 2004) or in cases of infanticide (Dunn et al., 2002; Patterson et al., 1998). Although contact behaviors could be effective in changing a receiver's behavior, frequent use of contact discipline could result in the injury or death of a small calf or juvenile, a risk that would not be outweighed by changing their behavior. No disciplinarian, mother or alloparent, would benefit from injuring or killing their own offspring or kin, and this may explain the infrequent use of contact behaviors during discipline in the spotted dolphin community.

Behaviors used in discipline-disciplinarians subsets. One of the main goals of this study was to determine what factors influenced the use of different behaviors by individuals when disciplining. The results of this suggest that little difference exists between disciplinarians based on age class, sex, parity, or relationship to the receivers (mother vs. alloparent). Many alloparent studies have suggested that alloparents are practicing parenting skills when babysitting, so it is likely they would implement similar behaviors observed to be used by mothers (Buchan, Alberts, Silk, \& Altmann, 2003; Forster \& Cords, 2005; Riedman, 1982; Maestripieri, 1999; Mann \& Smuts, 1998; Stone, Mathieu, Griffin, \& Bales, 2010; Strier, 2007). Furthermore, studies on male parental behavior have indicated that the parenting behaviors used by males are also similar to those used by mothers and female alloparents (Schradin \& Pillay, 2003; Schradin, Reeder, Mendoza, \& Anzenberger, 2003). It should be noted, however, that data in this study spanned thirteen years, and some dolphins were observed performing discipline in the earlier years of this study, and again in later years. This could have influenced the results because some dolphins performed the same behaviors over many years of raising their own calves and providing alloparental care towards the calves of others. This could be representative of a consistent maternal style, which has been observed in studies on primates and cetaceans, and may be true for female spotted dolphins while implementing discipline (Fairbanks, 1996; Francis, Young, Meaney, \& Insel, 2002; Hill et al., 2007; Maestripieri, 2011).

\section{Success in Discipline}

Varying disciplinary outcomes could be evidence for different animals and behaviors yielding more success than others. However, the results of this study suggested there were few differences in who performed discipline apart from age of the disciplinarian. Furthermore, this analysis found an almost equal amount of successful and unsuccessful disciplinary encounters. Despite the fact that adults were 
significantly more likely to perform discipline than juveniles, there was no evidence of adults achieving more success than juveniles. Other factors such as sex and parity did not appear to influence success in discipline either. These results may be due to small sample sizes, and more significant trends may have emerged if more samples of discipline were available. However, lack of significance could also be attributed to the nature of variables included in this study. For example, a factor such as parity may be a poor predictor of the success in discipline. Parity is based on how many times an individual has given birth; not necessarily how many successful offspring they have raised to independence. It is difficult to predict that multiparous females would have more success in parenting and discipline solely because they have had multiple offspring. A multiparous female may have given birth multiple times because their calves died, thus giving them more opportunities to reproduce. A primiparous female may have only given birth once, but may have more parenting experience by raising one successful calf or via alloparenting. Research on how parity affects parenting behavior is inconclusive. Although several studies have suggested differences in parenting behavior are related to parity (Hill, 2009; Lang, Boness, Bowen, \& Iverson, 2011; Maestripieri et al., 2009), others have shown that individual differences in maternal style are consistent over time and offspring (Champagne, Francis, Mar, \& Meaney, 2003; Hill et al., 2007).

The lack of difference in success rates may be also due to the fact that most individuals that performed discipline did so in a similar manner, and thus achieved similar rates of success and failure. All disciplinarians implemented all three behavioral categories of discipline; pursuit, contact, and display. Despite a lack of significance, there was evidence from the results of this study that pursuit and contact behaviors did yield more success in general than did display behaviors. Pursuit behaviors were widely used during discipline, and though not significantly different, the average duration of successful pursuits was shorter than that of unsuccessful pursuits. This may be due to the cost of being chased. Fleeing an incoming disciplinarian is energetically expensive, and may quickly motivate a receiver to stop their unwanted behavior and not perform it again. Short chases may also be related to the threat of discipline that a chase implies. In some cooperatively breeding animals, dominant individuals maintain cooperation and order in their society through the threat of costly punishment to an uncooperative individual (Jensen, 2010; Wong, Buston, Munday, \& Jones, 2007). Subdominant individuals in the population may choose to limit the frequency of unpopular behaviors to avoid being attacked or exiled from their social group or denied other social and reproductive benefits (Balshine-Earn, Neat, Reid, \& Taborsky, 1997; Johnstone \& Cant, 1999; Wong et al., 2007). Similarly, humans are considered a highly cooperative species and much of human societal law and order is based on the threat of costly punishment for the breaking of laws; including fines, jail time, and other legal action (Boyd et al., 2010; Seymour et al., 2007; Sigmund, 2007).

\section{Conclusion}

This study found that on Little Bahama Bank in the Bahamas, adult spotted dolphins, including mothers and alloparents, primarily discipline calves. Various behaviors are used in discipline, most notably a pursuit behavior such as an inverted chase. Pursuit behaviors yielded a relatively high success rate, and chases ended within seconds from their start. Within disciplinarians, factors such as age class, sex, and parity did not appear to influence how discipline was imparted nor its success rate.

The operational definition of discipline defined for spotted dolphins in this study may be applied to the behavior of parents, alloparents, and other social associates of the receivers of discipline. Future research may utilize this definition as it can be applied to other social animal communities in which disciplinary behavior is observed. Future research should also focus on defining the similarities and differences between punishment and discipline. Punishment has been examined in many animal species, though little comparison or distinction is made between it and discipline. Studies on punishment tend to 
include interactions between all individuals of a population, whereas discipline is generally considered in literature as occurring between parents and offspring. Detailed comparisons of punishment and disciplinary behavior would allow for a better understanding of the roles each play in social animal interactions.

Future research on discipline specifically should focus on exploring other aspects of discipline including what behaviors provoke disciplinary action, and how disciplinary styles affect survival of the offspring. This would allow for a more complete picture of the function of discipline in animal societies and how it is related to the fitness costs and benefits of living in a social group. Obtaining a large enough sample size to run powerful statistical tests is a common challenge in many animal behavior studies, and studies with larger sample sizes could strengthen the trends reported here. This project examined a small aspect of dolphin behavior that has never been explicitly analyzed, and the continued study of discipline will reveal insight into the nature of social behavior and cultural trends among group-living animals.

\section{References}

Altman, J. (1974). Observational study of behavior: Sampling methods. Behaviour, 49, 227-267.

$\mathrm{Au}, \mathrm{W}$. W. L (1997). Echolocation in dolphins with a dolphin-bat comparison. Bioacoustics, 8, $137-162$.

Ballance, L. T. (1992). Habitat use patterns and ranges of the bottlenose dolphin in the Gulf of California, Mexico. Marine Mammal Science, 8, 262-274.

Balshine-Earn, S., Neat, F. C., Reid, H., \& Taborsky, M. (1997). Paying to stay or paying to breed? Field evidence for direct benefits of helping behavior in a cooperatively breeding fish. Behavioral Ecology, 9, 432-438.

Bearzi, G., \& Politi, E. (1999). Diurnal behavior of free-ranging bottlenose dolphins in the Kvarneric (northern Adriatic sea). Marine Mammal Science, 15, 1065-1097.

Boyd, R., Gintis, H., \& Bowles, S. (2010). Coordinated punishment of defectors sustains cooperation and can proliferate when rare. Science, 328, 617-620.

Buchan, J. C., Alberts, S. C., Silk, J. B., \& Altmann, J. (2003). True paternal care in a multimale primate society. Nature, 425, 179-181.

Champagne, F. A., Francis, D. D., Mar, A., \& Meaney, M. J. (2003). Variations in maternal care in the rat as a meditating influence for the effects of environment on development. Physiology and Behavior, 79, 359371.

Clutton-Brock, T. H. (1991). The evolution of parental care. Princeton, NJ: Princeton University Press.

Clutton-Brock, T. H., \& Parker, G. A. (1995). Punishment in animal societies. Nature, 373, 209-215.

Conner, R. C., Smolker, R. A., \& Richards, A. F. (1992). Two levels of alliance formation among male bottlenose dolphins (Tursiops sp.). Proceedings of the National Academy of Sciences, 89,987-990.

Cords, M., Sheehan, M., \& Ekernas, L. S. (2010). Sex differences in juvenile social priorities in female philopatric nondespotic blue monkeys. American Journal of Primatology, 72, 193-205.

Cusick, J. A. (2012). Does size really matter? How synchrony and size affect the dynamic of aggression between two sympatric species of dolphins in the Bahamas (unpublished master's thesis). Florida Atlantic University, Boca Raton, FL.

Discipline. (2011). In Merriam Webster online. Retrieved from www.merriamwebster.com.

Dunn, D. G., Barco, S. G., Pabst, D. A., \& McLellan, W. A. (2002). Evidence for infanticide in bottlenose dolphins of the western north Atlantic. Journal of Wildlife Diseases, 38, 505-510.

Fairbanks, L. A. (1996). Individual differences in maternal style: causes and consequences for mothers and offspring. Advances in the Study of Behavior, 25, 579-611.

Forster, S., \& Cords, M. (2005). Socialization of infant blue monkeys (Cercopithecus mitis stuhlmanni) allomaternal interactions and sex differences. Behaviour, 142, 869-896.

Francis, D. D., Young, L. J., Meaney, M. J., \& Insel, T. R. (2002). Naturally occurring differences in maternal care are associated with the expression of oxytocin and vasopressin (V1a) receptors: Gender differences. Journal of Neuroendocrinology, 14, 349-353.

Gardner, A., \& West, S. A. (2004). Cooperation and punishment, especially in humans. The American Naturalist, $164,753-764$. 
Geise, L., Gomes, N., \& Cerqueira, R. (1999). Behaviour, habitat use and population size of Sotalia fluviatilis (Gervaise, 1853) (Cetacea, Dephindae) in the Cananeia estuary region, Sau Paulo, Brazil. Revista Brasileira de Biologia, 59, 183-194.

Green, M. L., Herzing, D. L., \& Baldwin, J. D. (2011). Reproductive success of male Atlantic spotted dolphins (Stenella frontalis) revealed by noninvasive genetic analysis of paternity. Canadian Journal of Zoology, 89, 239-253.

Herman, R. A., Measday, M. A., \& Wallen, K. (2003). Sex differences in interest in infants in juvenile rhesus monkeys: Relationship to prenatal androgen. Hormones and Behavior, 43, 573-583.

Herzing, D. L. (1997). The life history of free -ranging Atlantic spotted dolphins (Stenella frontalis): Age classes, color phases, and female reproduction. Marine Mammal Science, 13, 576-595.

Herzing, D. L. (2005). Transmission mechanisms of social learning in dolphins: Underwater observations of freeranging dolphins in the Bahamas. In F. Delfour \& M. J. Dubois (Eds.), Autour de l'ethologie et de la cognition animale (pp. 185 - 194). Lyon, France: Presses Universitaires de Lyon.

Herzing, D. L. (1996). Vocalizations and associated underwater behavior of free ranging Atlantic spotted dolphins, Stenella frontalis, and bottlenose dolphins, Tursiops truncatus. Aquatic Mammals, 22, 61-79.

Herzing, D. L., \& Brunnick, B. J. (1997). Coefficients of association of reproductively active female Atlantic spotted dolphins, Stenella frontalis. Aquatic Mammals, 23, 155-162.

Herzing, D. L., \& dos Santos, M. E. (2004). Functional aspects of echolocation in dolphins. In J.A. Thomas, C.F. Moss, \& M. Vater (Eds.), Echolocation in bats and dolphins. (pp 386-393). Chicago, IL: University of Chicago.

Herzing, D. L., \& Johnson, C. M. (1997). Interspecific interaction between Atlantic spotted dolphins (Stenella frontalis) and bottlenose dolphins (Tursiops truncatus) in the Bahamas, 1985-1995. Aquatic Mammals, 23, 85-99.

Hill, H. M. (2003). Mother calf interactions during the first year of life for bottlenose dolphins (Tursiops truncatus) (unpublished doctoral dissertation). University of Southern Mississippi, Hattiesburg, MS.

Hill, H. M., (2009). The behavioral development of two beluga calves during the first year of life. International Journal of Comparative Psychology, 22, 234-253.

Hill, H. M., Greer, T., Solangi, M., \& Kuczaj, S. A. (2007). All mothers are not the same: Maternal styles in bottlenose dolphins (Tursiops truncatus). International Journal of Comparative Psychology, 20, 35-54.

Hoffman, M. L., \& Saltzstein, H. D. (1967). Parent discipline and the child's moral development. Journal of Personality and Social Psychology, 5, 45-57.

Jensen, K. (2010). Punishment and spite, the dark side of cooperation. Philosophical Transactions of the Royal Society B, 365, 2635-2650.

Johnstone, R. A., \& Cant, M. A. (1999). Reproductive skew and the threat of eviction: A new perspective. Proceedings of the Royal Society B, 266, 275-279.

Kircaali-Iftar, G. (2005). How do Turkish mothers discipline children? An analysis from a behavioral perspective. Child: Care, Health and Development, 31, 193-201.

Kuczaj, S. A., Makecha, R., Trone, M., Paulos, R. D., \& Ramos, J. A. (2006). Role of peers in cultural innovation and cultural transmission: Evidence from the play of dolphin calves. International Journal of Comparative Psychology, 19, 223-240.

Lang, S. L. C., Boness, D. J., Bowen, W. D., \& Iverson, S. J. (2011). Primiparous females do not exhibit reduced maternal care in gray seals (Halichoerus grypus). Marine Mammal Science, 27, E153-E164.

Lusseau, D. (2007). Evidence for social role in a dolphin social network. Evolutionary Ecology, 21, $357-366$.

Maestripieri, D. (1999). Fatal attraction: Interest in infants and infant abuse in rhesus macaques. American Journal of Physical Anthropology, 110, 17-25.

Maestripieri, D. (2011). Emotions, stress, and maternal motivation in primates. American Journal of Primatology, 73, 516-529.

Maestripieri, D., Hoffman, C. L., Anderson, G. M., Carter, C. S., \& Higley, J. D. (2009). Mother-infant interactions in free-ranging rhesus macaques: relationships between physiological and behavioral variables. Physiology \& Behavior, 96(4), 613-619.

Maestripieri, D., \& Pelka, S. (2002). Sex differences in interest in infants across the lifespan. A biological adaptation for parenting? Human Nature, 13, 327-344. 
Mann, J., \& Smuts, B. B. (1998). Natal attraction: Allomaternal care and mother-infant separations in wild bottlenose dolphins. Animal Behavior, 55, 1097-1113.

Mann, J., \& Smuts, B. (1999). Behavioral development in wild bottlenose dolphin newborns (Tursiops sp.). Animal Behaviour, 136, 529-566.

Mann, J., Stanton, M. A., Patterson, E. M., Bienenstock, E. J., \& Singh, L. O. (2012). Social network reveal cultural behaviours in tool-using using dolphins. Nature Communications, 3, 1-7.

Martin, P., \& Bateson, P. (2007). Measuring behavior: An introductory guide. New York: Cambridge University Press.

McCowan, B., \& Reiss, D. (1995). Maternal aggressive contact vocalizations in captive bottlenose dolphins (Tursiops truncatus): Wide-band, low frequency signals during mother/aunt-infant interactions. Zoo Biology, 14, 293-310.

McLoyd, V. C., \& Smith, J. (2002). Physical discipline and behavior problems in African American, European American, and Hispanic children. Journal of Marriage and Family, 64, 40-53.

Miles, J. A., \& Herzing, D. L. (2003). Underwater analysis of the behavioral development of free ranging Atlantic spotted dolphin (Stenella frontalis) calves (birth to 4 years of age). Aquatic Mammals, 29, 363-377.

Patterson, I. P., Reid, R. J., Wilson, B., Grellier, K., Ross, H. M., \& Thompson, P. M. (1998). Evidence for infanticide in bottlenose dolphins: An explanation for violent interactions with harbor porpoises? Proceedings of the Royal Society B, 265, 1167-1170.

Regalado, M., Sareen, H., Inkeles, M., Wissow, L. S., \& Halfon, N. (2004). Parent's discipline of young children: Results from the national survey of early childhood health. Pediatrics, 113, 1952-1958.

Rendell, L., \& Whitehead, H. (2001). Culture in whales and dolphins. Behavioral and Brain Sciences, $24,309-382$.

Riedman, M. L. (1982). The evolution of alloparental care and adoption in mammals and birds. The Quarterly Review of Biology, 57,405-435.

Riedl, K., Jensen, K., Call, J., \& Tomasello, M. (2012). No third-party punishment in chimpanzees. Proceedings of the National Academy of Sciences, 109(37), 14824-14829.

Schradin, C., \& Pillay, N. (2003). Paternal care in the social and diurnal striped mouse (Rhabdomys pumilio): Laboratory and field evidence. Journal of Comparative Psychology, 117, 317-324.

Schradin, C., Reeder, D. M., Mendoza, S. P., \& Anzenberger, G. (2003). Prolactin and paternal care: Comparison of three species of monogamous new world monkeys (Callicebus cupreus, Callithrix Jacchus, and Callimico goeldii). Journal of Comparative Psychology, 117, 166-175.

Scott, E. M., Mann, J., Watson-Capps, J. J., Sargeant, B. L., \& Connor, R. C. (2004). Aggression in bottlenose dolphins: Evidence for sexual coercion, male-male competition, and female tolerance through analysis of tooth-rake marks and behavior. Behaviour, 142, 21-44.

Seymour, B., Singer, T., \& Dolan, R. (2007). The neurobiology of punishment. Nature, 8, 300-311.

Sigmund, K. (2007). Punish or perish? Retaliation and collaboration among humans. TRENDS in Ecology and Evolution, 22, 593-600.

Stone, A. I., Mathieu, D., Griffin, L., \& Bales, K. L. (2010). Alloparenting experience affects future parental behavior and reproductive success in prairie voles (Microtus ochrogaster). Behavior Processes, 83, 8-15.

Strier, K. B. (2007). Primate Behavioral Ecology (3rd ed.). Boston: Pearson Education, Inc.

Thewissen, J. G. M. (2008). Functional systems. In W. F. Perrin, B. Wursig, J. G. M. Thewissen (Eds.), Encyclopedia of marine mammals (1 $1^{\text {st }}$ ed., Vol. 1). New York: Academic Press.

Waitt, C., Maestripieri, D., \& Gerald, M. S. (2007). Effects of parity and age on female attraction to faces of infants and neonates in rhesus macaques. Primates, 48, 164-167.

Wong, M. Y. L., Buston, P. M., Munday, P. L., \& Jones, G. P. (2007). The threat of punishment enforces peaceful cooperation and stabilizes queues in a coral-reef fish. Proceedings of the Royal Society B, 274, 1093-1099. 